\title{
Vivir Bien: ¿Paradigma no capitalista? Ivonne Farah H. / Luciano Vasapollo (Coordinadores)
}

\author{
Universidad Mayor de San Andrés (CIDES-UMSA) y \\ Departamento de Economía de la Universidad de Roma La \\ Sapienza, 2011, 437 págs. \\ Carlos Perea Sandoval
}

Universidad Santo Tomás, Bucaramanga, Colombia. Email: intiibis@gmail.com

La humanidad se encuentra en una constante búsqueda por construir una ética que permita hacer realidad el re-ligarse con el futuro, lo cual implica generar una convivencia recíproca con la naturaleza y las demás formas de vida, en el camino de la ética del bien común. La construcción de este modelo ético se constituye en una prioridad ya que desde el mismo es posible determinar caminos de acción, que a partir de una postura social y de apoyo mutuo, se concrete en alternativas para enfrentar el modelo del individualismo y la competencia.

En el marco de esta tarea de humanidad surge el diseño del Vivir Bien, que desde el accionar humano propende por establecer los horizontes y condiciones de posibilidad de un nuevo paradigma de ocurrencia de la vida social y natural.

Esta apuesta por consolidar la ética del Vivir Bien, tanto en los aspectos conceptuales, como valorativos y prácticos, es expresada en los contenidos del libro Vivir Bien: ¿Paradigma no capitalista?, en el cual un grupo de investigadores sociales, desde diferentes posturas disciplinares y políticas asumen el reto de plantear principios para la generación de una nueva convivencia que se constituya en una alternativa viable al modelo del capital imperante.

Presentar a la humanidad una propuesta de tal envergadura, ha implicado que se establezca un cerebro social en el cual se incluye las experiencias de vida de diversos sectores de la población, especialmente de los indígenas de Bolivia y Ecuador, articuladas con las experiencias de gobernabilidad y políticas públicas, como el aporte de un grupo de intelectuales que comprometidos por la causa de una nueva humanidad, han abordado la reflexión del Vivir Bien, desde el campo económico, social, político y multicultural.

La obra reseñada es el resultado de la convocatoria conjunta entre el Postgrado en Ciencias del Desarrollo de la Universidad Mayor de San An- 
drés (CIDES - UMSA) y el Departamento de Economía de la Universidad de Roma La Sapienza, en el marco de un Convenio de Colaboración académica entre ambas Universidades.

Es una obra de humanidad en humanidad, que tiene como fin contribuir a la reflexión académica y política sobre la noción del Vivir Bien y sus posibilidades para constituirse en el soporte ético que ilumine un nuevo paradigma de producción y reproducción de la realidad social.

El prólogo de la obra es realizado por Evo Morales, presidente de Bolivia, que desde su experiencia como indígena Aymara, gobernador y ejecutor de políticas públicas da un testimonio del significado que tiene para los habitantes de su país el Vivir Bien, y la necesidad de que la humanidad conozca los fundamentos de esta propuesta.

Evo enfatiza como "El Vivir Bien es una forma de vida, de relacionamiento con la naturaleza, de complementariedad entre los pueblos, es parte de la filosofía y la práctica de los Pueblos Indígenas. Asimismo, no sólo desnuda las causas estructurales de las crisis (alimenticia, climática, económica, energética) que vive nuestro planeta, sino que plantea una profunda crítica al sistema que está devorando a seres humanos y a la naturaleza: el sistema capitalista mundial.

Continúa el mandatario denunciando que "mientras los Pueblos Indígenas proponen para el mundo el Vivir Bien, el capitalismo se basa en el Vivir Mejor. Las diferencias son claras: El vivir mejor significa vivir a costa del otro, explotando al otro, saqueando los recursos naturales, violando a la Madre Tierra, privatizando los servicios básicos; en cambio el Vivir Bien es vivir en solidaridad, en igualdad, en armonía, en complementariedad, en reciprocidad. En términos científicos, desde el marxismo, desde el leninismo dice: socialismo-capitalismo; y nosotros sencillamente decimos: el vivir bien y el vivir mejor.

En este marco, planteado por Evo Morales, toma sentido el cuerpo de la obra, cuya compilación y organización la realizan Ivonne Farah H. y Luciano Vasapollo. Los contenidos de la obra son presentados en cinco bloques, que aunque en ellos se aborden cuestiones particulares, sin embargo constituyen una totalidad, que permite al lector tener una visión holística del Vivir Bien.

Un primer tema abordado hace referencia al sentido semántico y filosófico del Vivir Bien. La lectura de este bloque promueve la comprensión del concepto a partir de campos semánticos propios generados desde una manera cultural, que ligados a una concepción de vida, permiten establecer diferencias y distancias con otras acepciones construidas a partir de campos semánticos ligados a las lógicas occidentales y al modo de producción capitalista. En los contendidos tratados en esta primera parte, sentires, vivencias mágicas, espiritualidades y cosmogonías toman fuerza desde lo propio de nuestras culturas, para darle significado al Vivir Bien. 
Una vez presentada la concepción del Vivir Bien, desde nuestra manera cultural, en una segunda parte se aborda los horizontes que emergen desde él. En especial se profundiza en el horizonte ético, entendido como el camino hacia una ética del bien común. Los autores proponen principios y postulados de esta nueva ética, lo cual implica, entre otros, la utilización sostenible y responsable de los recursos naturales, el privilegio del valor de uso sobre el valor de cambio, la ampliación de la democracia, la multiculturalidad, la cooperación solidaria, la socialización y gestión colectiva de la riqueza social.

El emerger de este nuevo horizonte ético implica la necesidad de eliminar los patrones de desarrollo existentes en el modelo capitalista y consolidar nuevos patrones que se correspondan con el Vivir Bien. Los autores en este bloque hacen un llamado a imaginar otros mundos en los que la calidad de vida, la cuestión ambiental y la recreación de lo humano en lo humano, se constituyan en accionares que garanticen repensar una nueva visión de desarrollo, que se contraponga a la que, desde las visiones del capital, se impusieron en nuestro territorio.

Diseñar y ejecutar estos nuevos patrones de desarrollo, implica la consolidación e instalación de la conciencia del Vivir Bien en las diversas organizaciones humanas. Este proceso de concientización exige un compromiso de los actores e instituciones sociales los cuales deben modificar sus prácticas y concepciones. Los autores abordan en este bloque problemáticas propias de los procesos de construcción de nuevos conocimientos, especialmente lo relacionado con el papel de las Universidades en la formación de profesionales que den respuesta a las exigencias del vivir bien, desde la óptica socioambiental, política, económica y cultural.

El último bloque del libro nos acerca a una experiencia real del Vivir Bien, que se está llevando en Bolivia. Esta experiencia permite abordar reflexiva y críticamente los procesos de colonización y la necesidad de impulsar la descolonización, ubicar la importancia del vivir bien desde la geopolítica e impulsar el desarrollo endógeno sustentable y articular las políticas públicas al Vivir Bien.

La importancia de la obra reseñada radica en que a partir del sentido expresado en sus contenidos es posible llevar una reflexión crítica de las prácticas, concepciones y comportamientos del modelo del capital e identificar los elementos de des-humanización presentes en el mismo. Pero de igual manera, la obra pone a sus lectores en contacto con principios y procedimientos de una ética de humanidad en humanidad, a partir de la cual se hace un llamado para reconfigurar nuevos accionares que, apartados del modelo del capital, se constituyan en alternativas de construcción y consolidación de un mundo mejor. 